\title{
Erratum to: Osmo-dehydration of apple pulp studied by means of classical and Knudsen Thermogravimetric approach
}

\author{
Paola Pani · Marco Signorelli • Alberto Schiraldi • \\ Danila Torreggiani
}

Published online: 19 June 2010

(C) Akadémiai Kiadó, Budapest, Hungary 2010

\section{Erratum to: J Therm Anal Calorim \\ DOI 10.1007/s10973-009-0544-z}

Unfortunately, in the original publication Fig. 9 was mistaken and has to be replaced with the following one.

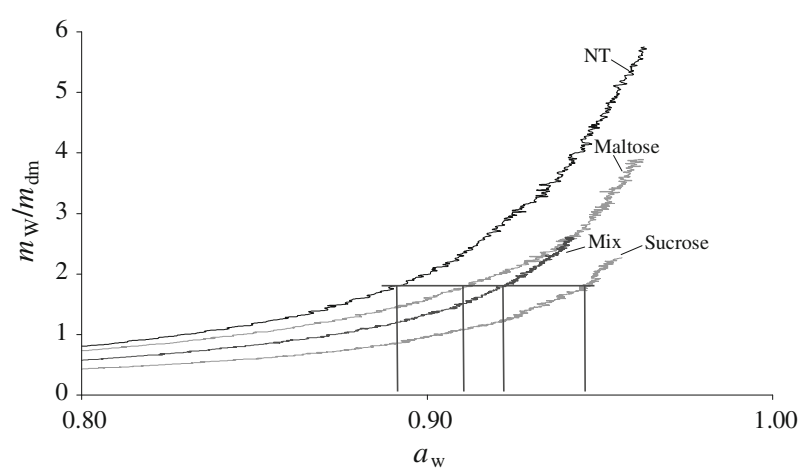

Fig. 9 Desorption isotherms of apple pulp after one hour osmodehydration with different hypertonic syrups. NT stands for non treated sample
Consistently, the relevant comment has to be changed in:

At a given moisture content, the RH of apple pulp treated with any sugar hypertonic syrup is larger than that of non treated (NT) samples, although in the order $\mathrm{RH}$ (Maltose) $<\mathrm{RH}(\mathrm{MIX})<\mathrm{RH}$ (sucrose). This finding suggests that osmo-dehydration actually implies not only water withdrawing, but also some sugar exchange between the apple pulp and the dehydrating sugar syrup.

The online version of the original article can be found under doi: 10.1007/s10973-009-0544-z.

P. Pani $(\bowtie) \cdot$ M. Signorelli · A. Schiraldi

DISTAM University of Milan, Via Celoria 2, 20133 Milan, Italy

e-mail: paola.pani@unimi.it

D. Torreggiani

CRA-IAA, Via Venezian 26, 20133 Milan, Italy 